\title{
COL25A1 triggers and promotes Alzheimer's disease-like pathology in vivo
}

\author{
Ying Tong $•$ Ying $\mathrm{Xu} \cdot$ Kimberly Scearce-Levie • \\ Louis J. Ptáček • Ying-Hui Fu
}

Received: 13 March 2009 / Accepted: 28 May 2009/Published online: 23 June 2009

(C) The Author(s) 2009. This article is published with open access at Springerlink.com

\begin{abstract}
Collagen XXV alpha 1 (COL25A1) is a collagenous type II transmembrane protein purified from senile plaques of Alzheimer's disease (AD) brains. COL25A1 alleles have been associated with increased risk for $\mathrm{AD}$ in a Swedish population. COL25A1 is specifically expressed in neurons and binds to aggregated $A \beta$ in vitro. However, its contribution to the pathogenesis of $\mathrm{AD}$ and in vivo function are unknown. Here, we report that over-expression of COL25A1 in transgenic mice increases $\mathrm{p} 35 / \mathrm{p} 25$ and $\beta$-site APP-cleaving enzyme 1 (BACE1) levels, facilitates intracellular aggregation and extracellular matrix deposits of $\mathrm{A} \beta$, and causes synaptophysin loss and astrocyte activation. COL25A1 mice displayed reduced anxiety-like behavior in elevated plus maze and open field tests and significantly slower swimming speed in Morris water maze. In stable cell lines, motifs in noncollagenous domains of COL25A1 were
\end{abstract}

Electronic supplementary material The online version of this article (doi:10.1007/s10048-009-0201-5) contains supplementary material, which is available to authorized users.

Y. Tong · Y. Xu • L. J. Ptáček · Y.-H. Fu $(\bowtie)$

Department of Neurology, University of California San Francisco, 1550 Fourth Street, Rock Hall Rm548,

San Francisco, CA 94158, USA

e-mail: ying-hui.fu@ucsf.edu

Y. Tong · L. J. Ptáček

Howard Hughes Medical Institute,

University of California San Francisco,

San Francisco, CA 94158, USA

Y. Tong

College of Life Science, Sichuan University,

Chengdu 610064 Sichuan, China

K. Scearce-Levie

Gladstone Institute of Neurological Disease,

San Francisco, CA 94158, USA important for the induction of BACE1 expression. These findings demonstrate that COL25A1 leads to AD-like pathology in vivo. Modulation of COL25A1 function may represent an alternative therapeutic intervention for $\mathrm{AD}$.

Keywords COL25A1 A Alzheimer's disease - Amyloid $\beta$. BACE1 $\cdot$ p25 C Cdk5

\section{Introduction}

According to the prevailing "amyloid cascade" hypothesis, the pathogenesis of Alzheimer's disease (AD) is driven primarily by amyloidosis, a gradual abnormal accumulation of $A \beta$ [1]. $A \beta$ is a proteolytic product of amyloid precursor protein (APP) metabolism, generated by sequential cleavage by $\beta$-secretase ( $\beta$-site APP-cleaving enzyme 1, BACE1) and $\gamma$-secretase. Dysfunction of BACE1 and $\gamma$-secretase inevitably causes aberrant APP processing, production of toxic $\mathrm{A} \beta$ species, and amyloidogenesis. Although no BACE1 mutation has been identified in $\mathrm{AD}, \mathrm{BACE} 1$ protein and activity levels are significantly increased in AD brains [2], and elevated BACE1 levels increase $A \beta$ production in $B A C E 1$ transgenic (TG) mice $[3,4] . \mathrm{A} \beta$ is produced as a monomer, but readily aggregates to form oligomeric complexes, and further assembles to form fibrils.

Dysregulation of cyclin-dependent kinase 5 (Cdk5) has been suggested to be one of the downstream processes affected by $A \beta$ toxicity $[5,6]$. Cdk5 is expressed in most tissues, but its neuron-specific activator $\mathrm{p} 35 / \mathrm{p} 25$ restricts its activity largely to neurons. p25 and Cdk5 activities are increased in human $\mathrm{AD}$ brains [7,8]. Elevated p25 was recently shown to increase $A \beta$ production, an effect that was mediated by an increase in BACE1 levels and reversed with a pharmacological inhibitor $[9,10]$. These data 
demonstrate a positive regulatory loop between $A \beta$ and p35/p25.

Collagen XXV alpha 1 (COL25A1), also known as collagen-like Alzheimer's amyloid plaque component precursor, is a newly identified type II transmembrane protein specifically expressed in neurons that colocalizes with $A \beta$ in senile plaques in AD brains [11, 12]. Previously, a modest association between SNPs of COL25Al and increased AD risk was reported in a Swedish population [13]. The primary structure of COL25A1 is composed of three collagenous domains (COL1-3) flanked by four noncollagenous domains (NC1-4). The N-terminal NC1 domain contains a short cytoplasmic domain, a transmembrane domain, and an extracellular ectodomain which harbors a furin cleavage site. Proteolytic processing by furin releases the COL25A1 C-terminus to the extracellular matrix. COL25A1 binds specifically to $A \beta$ fibrils in vitro, slows their elongation, and facilitates their assembly into aggregates with increased resistance to proteases [14-16]. It is not known whether COL25A1 contributes to the pathogenesis of $\mathrm{AD}$ in vivo.

To investigate the role of COL25A1 in the pathogenesis of $\mathrm{AD}$, we assessed the effects of COL25A1 overexpression on $\mathrm{A} \beta, \mathrm{p} 35 / \mathrm{p} 25$, and BACE1 levels in TG mice. The effect on synaptophysin and astrocyte were examined. We also carried out behavioral analyses. In addition, we evaluated the importance of $\mathrm{NC} 1, \mathrm{NC} 2$, and $\mathrm{NC} 3$ domains of COL25A1 in the induction of BACE1 in stably transfected SH-SY5Y cell lines. Our findings provide in vivo evidence that COL25A1 plays a critical role in $\mathrm{AD}$ pathogenesis.

\section{Materials and methods}

Generation of TG mice

Human COL25A1 complementary DNA (cDNA; GenBank accession no. AF293340 nt507-2588, splice variant without nt952-969; corresponding protein AAK35008 without aa141-146 in COL1 domain) was amplified and subcloned into a Thy-1.2 expression cassette (kind gift from Dr. Corinna Schneider) at a XhoI site. Transgenic founders were produced on a (C57BL/6 X SJL) $\mathrm{F}_{2}$ background. Two pairs of primers were used to identify and confirm TG mice: CLAC6f: 5'-GATGGAGAGCCTGGTC TTGATG-3' and CLAC6r: 5'-GGATGATGGCATGCAGCACTG-3' (polymerase chain reaction (PCR) product, $335 \mathrm{bp}$ ); and CLAC7f: 5'-CCTTGGCTTTCTCTGAGTGGCA-3' and CLAC5r: 5'-AGTCGCTCCACTTT CTCTTGCAC-3' (PCR product, $491 \mathrm{bp}$ ). Two founders (861 and 797) with abundant transgene expression were selected and backcrossed onto the C57BL/6J (Charles River Laboratories) background. The studies reported here were all conducted on line 861; some findings were confirmed in line 797 .

\section{Immunostaining}

Immunohistochemical staining was performed as described [17] with slight modifications. Free-floating $20-\mu \mathrm{m}$ coronal sections were collected serially into cryoprotectant medium (30\% glycerol $/ 30 \%$ ethylene-glycol in phosphate-buffered saline) and kept at $-20^{\circ} \mathrm{C}$. Sections were pretreated with $1 \% \mathrm{H}_{2} \mathrm{O}_{2} / 10 \%$ methanol/phosphatebuffered saline for $10 \mathrm{~min}$ at room temperature to quench endoperoxidase activity. The primary antibodies were rabbit anti-NC4 (1:600, kind gift from Dr. Takeshi Iwatsubo), rabbit anti-human beta-amyloid 1-40/42 (AB5076, Chemicon, Temecula, CA, USA; 1:200) [18, 19], mouse anti-BACE1 (MAB5308, Chemicon; 1:500), rabbit anti-cdk5r1(p35) (sc-820, C-19, Santa Cruz Biotechnology, Santa Cruz, CA, USA; 1:100), and mouse anti-glial fibrillary acidic protein (GFAP; MAB360, Chemicon; 1:600). The secondary antibodies were biotinylated goat anti-rabbit or mouse IgG (Vector Laboratories, Burlingame, CA, USA; 1:500). Reaction products were visualized with the $\mathrm{ABC}$ Elite kit (Vector Laboratories), diaminobenzidine, and $\mathrm{H}_{2} \mathrm{O}_{2}$. Sections were then mounted, dehydrated, cleared, and cover-slipped with Cytoseal-60 (Electron Microscopy Science, Hatfield, PA, USA). For immunofluorescence staining, Cy3conjugated AffiniPure goat anti-rabbit IgG (Jackson Immuno Research Laboratories, West Grove, PA, USA) was used as the secondary antibody.

\section{Western blotting}

Snap-frozen forebrain samples were homogenized in crude extraction buffer $(20 \mathrm{mM}$ Tris-HCl, $\mathrm{pH} 7.4,5 \mathrm{mM}$ ethylenediamine tetraacetic acid (EDTA), $150 \mathrm{mM} \mathrm{NaCl}, 1 \%$ Triton X-100) with an EDTA-free protease inhibitor cocktail (Complete, Roche, Indianapolis, IN, USA). SHSY5Y cells were harvested in cold phosphate-buffered saline from $90-\mathrm{mm}$ dishes and snap frozen. Clones were collected in modified RIPA buffer $(25 \mathrm{mM}$ Tris- $\mathrm{HCl}, \mathrm{pH}$ 7.6, $5 \mathrm{mM}$ EDTA, $150 \mathrm{mM} \mathrm{NaCl}, 1 \%$ Triton X-100, 0.1\% sodium dodecyl sulfate, $1 \%$ deoxycholate, $1 \mathrm{mM}$ phenylmethylsulfonyl fluoride) with protease inhibitor cocktail and centrifuged at 15,000 rpm for $15 \mathrm{~min}$. The supernatants were collected, and protein concentrations were determined by BCA protein assay (Pierce, Rockford, IL, USA). Samples were separated on standard sodium dodecyl sulfate-polyacrylamide gels, transferred to membranes, and analyzed by Western blotting. The primary antibodies were mouse anti-synaptophysin (MAB5258,Chemicon; 1:4,000), mouse anti-BACE1 (MAB5308, Chemicon; 
1:1,000), mouse anti- $\alpha$-tubulin (Sigma-Aldrich, St. Louis, MO, USA; 1:1,000,000) or mouse anti-glyceraldehyde-3phosphate dehydrogenase (GAPDH; MAB374A, Chemicon; 1:80,000). Secondary antibodies were horseradish peroxidase-labeled goat anti-mouse IgG (sc-2005, Santa Cruz Biotechnology; 1:2,000). Labeling was detected with the ECL system (Amersham Biosciences, Pittsburgh, PA, USA). Densitometric software (Kodak ID 3.6) was used to quantify bands relative to the endogenous control (tubulin or GAPDH), and the values were normalized to those of wild-type (WT) controls.

\section{Behavioral tests}

Age-matched 12-20-month-old male COL25A1 TG ( $n=13)$ and non-TG littermates $(n=22)$ underwent a series of behavioral tests. The experimenter was blinded to the genotypes during testing. First, mice were tested in an elevated, plus-shaped maze consisting of two open arms and two closed arms equipped with rows of infrared photocells interfaced with a computer (Hamilton-Kinder, Poway, CA, USA). Briefly, mice were placed individually in the center of the maze and allowed free access for $10 \mathrm{~min}$. The time spent and distance moved in each of the arms and the number of times the mice extended over the edges of the open arms was calculated from recorded infrared beam breaks for each 5-min interval of testing. The main difference in anxiety was found in the first $5 \mathrm{~min}$. Next, in the novel field test, mice were placed in a open chamber (16 in. $\times 16$ in.) and allowed to explore freely for 15 min. Activity was recorded by an array of infrared photocells interfaced with a computer (Photobeam Activity System, San Diego Instruments, San Diego, CA, USA) that can detect and distinguish horizontal ambulatory movements, fine movements, and vertical movements (rearing). The center of the field was defined as the central $4 \mathrm{in} . \times 4 \mathrm{in}$. square. Finally, mice were tested in the Morris water maze. Mice were trained to find a platform $(14 \mathrm{~cm} \times 14 \mathrm{~cm})$ submerged $1.5 \mathrm{~cm}$ below the surface of the water $\left(18 \pm 2^{\circ} \mathrm{C}\right)$, made opaque with nontoxic tempera powder in a $122-\mathrm{cm}$ pool. Mice were pretrained to remain on the platform in a series of four trials in which they were placed in a restricted $(14 \mathrm{~cm} \times 122 \mathrm{~cm})$ alley within the pool and allowed to swim until they encountered the platform. If the mouse did not find the platform within $90 \mathrm{~s}$, the mouse was led to the platform by hand, placed on it, and allowed to sit for $5 \mathrm{~s}$. After 1 day of pretraining, mice were trained to find a visibly cued platform, marked with a $10-\mathrm{cm}-$ high, black-and-white striped marker affixed to the center of the platform. Mice were trained in two daily sessions of two trials each over three consecutive days. Then, mice were trained to find a hidden platform in two daily sessions of three trials each over five consecutive days. For both cued and hidden platform training, the intertrial interval was $10 \mathrm{~min}$, and the time between sessions was $3 \mathrm{~h}$. Maximum trial length was $60 \mathrm{~s}$. Time to reach the platform (latency), path length, and swim speed were recorded with an EthoVision video tracking system (Noldus, The Netherlands). Probe trials were performed $18 \mathrm{~h}$ after the 18th and 30th trials of hidden platform training. For each 60 -s probe trial, the platform was removed from the pool, and the amount of time the mouse spent searching in the target quadrant was recorded.

Analysis of variance (ANOVA) was performed to detect the effect of genotype in the elevated plus maze and open field test. For Morris water maze testing, the main effects and interactions between genotype and session or probe trials were assessed by repeated-measures ANOVA.

Plasmid constructs and cell culture

Human COL25A1 cDNA coding region (full-length or with designed deletion, GeneBank accession no. AF293340, splice variant without nt952-969) was amplified by PCR, subcloned into the pEGFPC3 vector (Clontech, BD Biosciences, Mountain View, CA, USA; GenBank accession no. U57607) and confirmed by sequencing. Constructs were designated as follows: WT, full-length cDNA coding region; $\triangle \mathrm{COL} 1, \Delta \mathrm{aa} 123-162 ; \Delta \mathrm{NC} 1, \Delta \mathrm{aa} 56-95 ; \Delta \mathrm{NC} 2, \Delta \mathrm{aa} 165-$ 188; $\triangle \mathrm{NC} 3, \Delta \mathrm{aa} 421-444$ (corresponding to GeneBank accession no. AAK35008). Human neuroblastoma SHSY5Y cells (American Type Culture Collection, Manassas, VA, USA) were cultured in Dulbecco's modified Eagle's medium/F-12 medium (Invitrogen, Carlsbad, CA, USA) supplemented with $10 \%$ fetal bovine serum (Hyclone, Logan, UT, USA) and $100 \mathrm{U} / \mathrm{ml}$ penicillin/streptomycin in a humidified $5 \% \mathrm{CO}_{2}$ at $37^{\circ} \mathrm{C}$. Lipofectamine 2000 (Invitrogen) was used for transfections. Stable cell lines were selected with $200 \mu \mathrm{g} / \mathrm{ml}$ geneticin (Invitrogen), induced to differentiate with $10 \mu \mathrm{M}$ retinoic acid (Sigma-Aldrich) for 5 days, and harvested for Western blot analysis.

\section{Results}

COL25A1 expression in TG mouse brain

TG mice were generated with a human COL25A1 cDNA driven by the murine Thy 1.2 promoter, and two independent lines (861 and 797) were maintained. TG human COL25A1 and endogenous mouse Col25a1 were distinguished immunohistochemically with a human-specific antibody against NC4 (Fig. 1). In 2-month-old TG mice, cortical neurons stained positively for $\mathrm{NC} 4$ primarily in cell membranes, suggesting that the detected protein was the precursor form of COL25A1 (Fig. 1a). In 6-month-old TG mice, NC4 staining of the COL25A1 precursor was strong in the cortex, CA1 pyramidal neurons, dentate gyrus (DG), 
granule neurons, and thalamic cells (Fig. 1b). Secreted forms of COL25A1 were detected in extracellular matrix (ECM) of cortex and DG and formed fibrillar ECM deposits in 6-month-old mice. In 1-year-old mice, both forms of COL25A1 were strongly detected in whole brain, including cortex, hippocampus, and thalamus (Fig. 1c). These results suggest that the murine Thy1.2 expression cassette drives COL25A1 expression in a temporal-spatial pattern beginning in the cortex and progressing to the hippocampus.

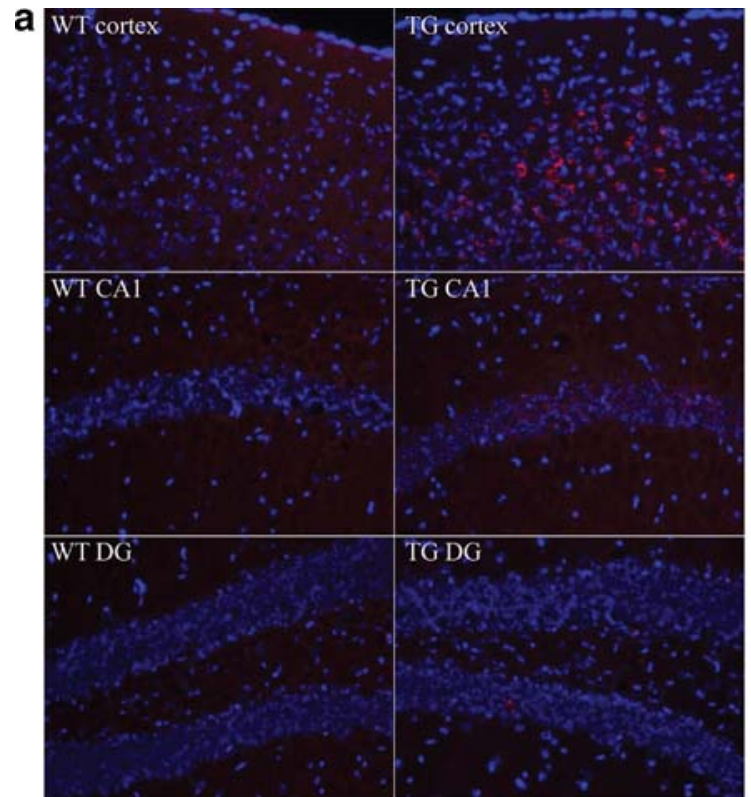

C

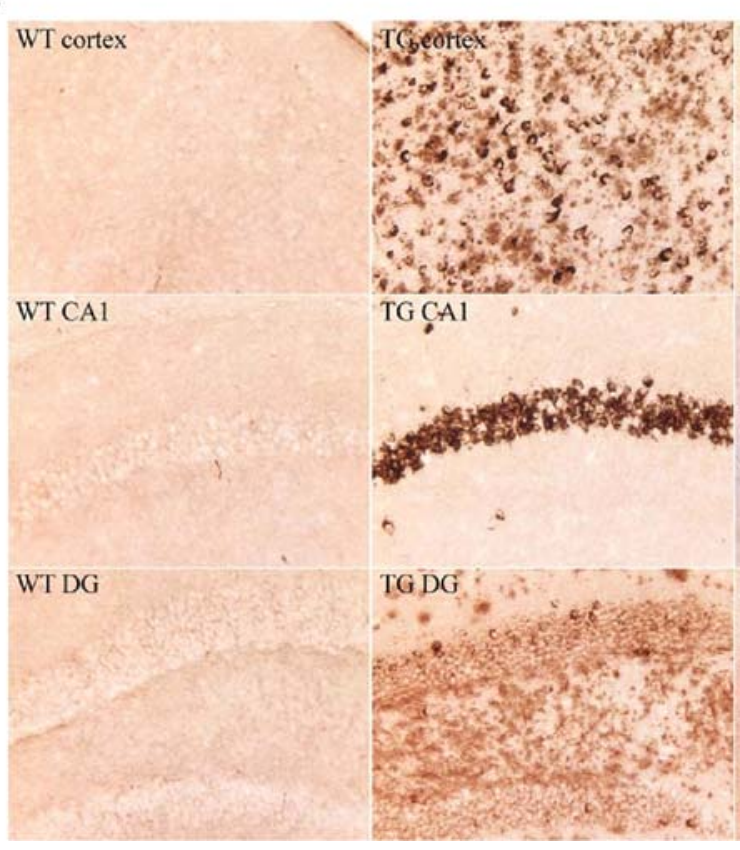

Fig. 1 COL25A1 expression in TG mice begins in cortex and progresses to hippocampus. a Immunofluorescence staining of 2month-old mouse brains. Cortical neurons were stained with NC4 antibody (red) in TG mice but not in WT littermate controls. Sections were counterstained with DAPI to identify nuclei (blue). b Immunofluorescence staining of 6-month-old mouse brains. Cortex, CA1, and DG were stained with $\mathrm{NC} 4$ antibody (red) in TG mice; the
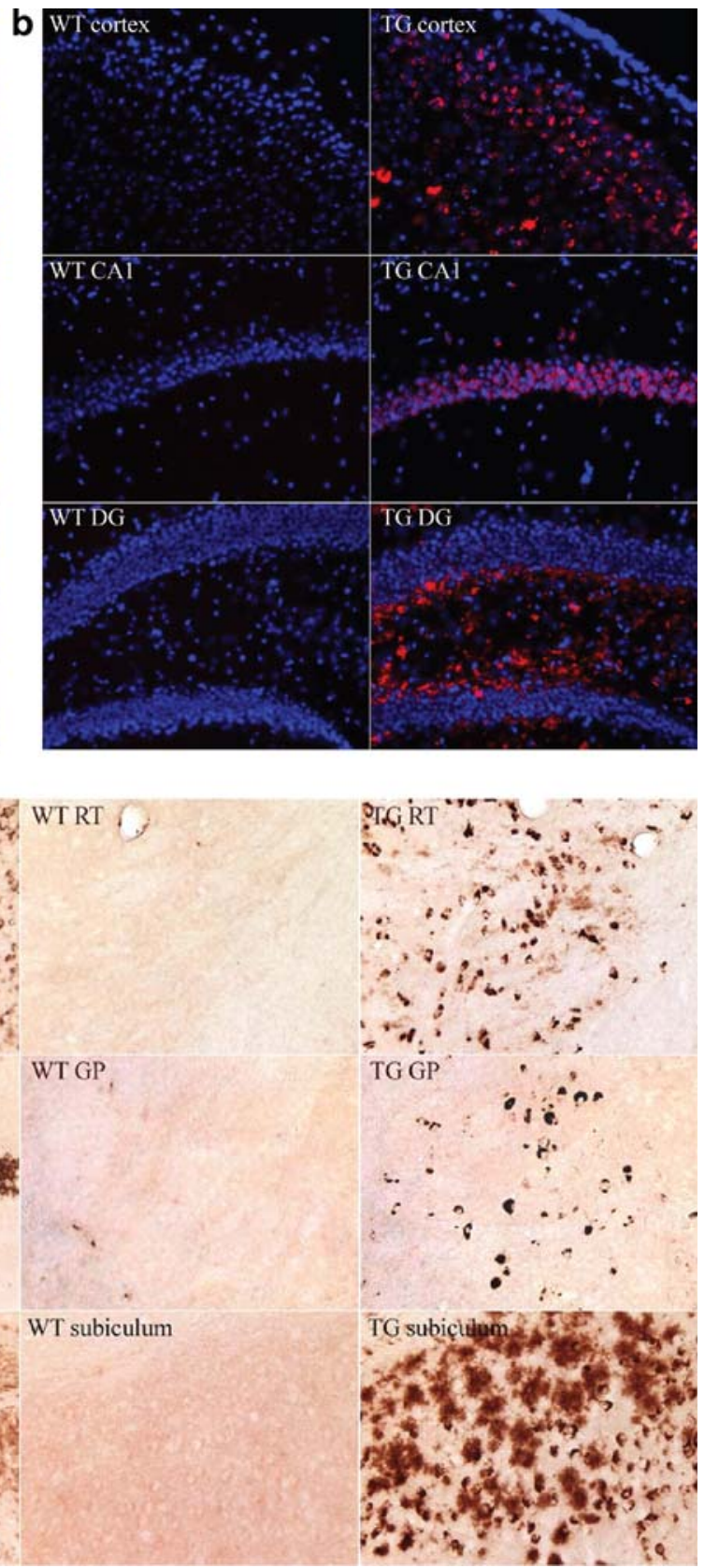

extracellular secreted form of COL25A1 was also detected in the DG. WT littermates showed no staining. c Immunohistochemical staining of 1-year-old mouse brains. NC4 staining was prominent in cortex, CA1, DG, reticular thalamic nuclei $(R T)$, globus pallidus $(G P)$, and subiculum in TG but not in WT control mice. Both precursor and secreted forms of COL25A1 were detected 
a

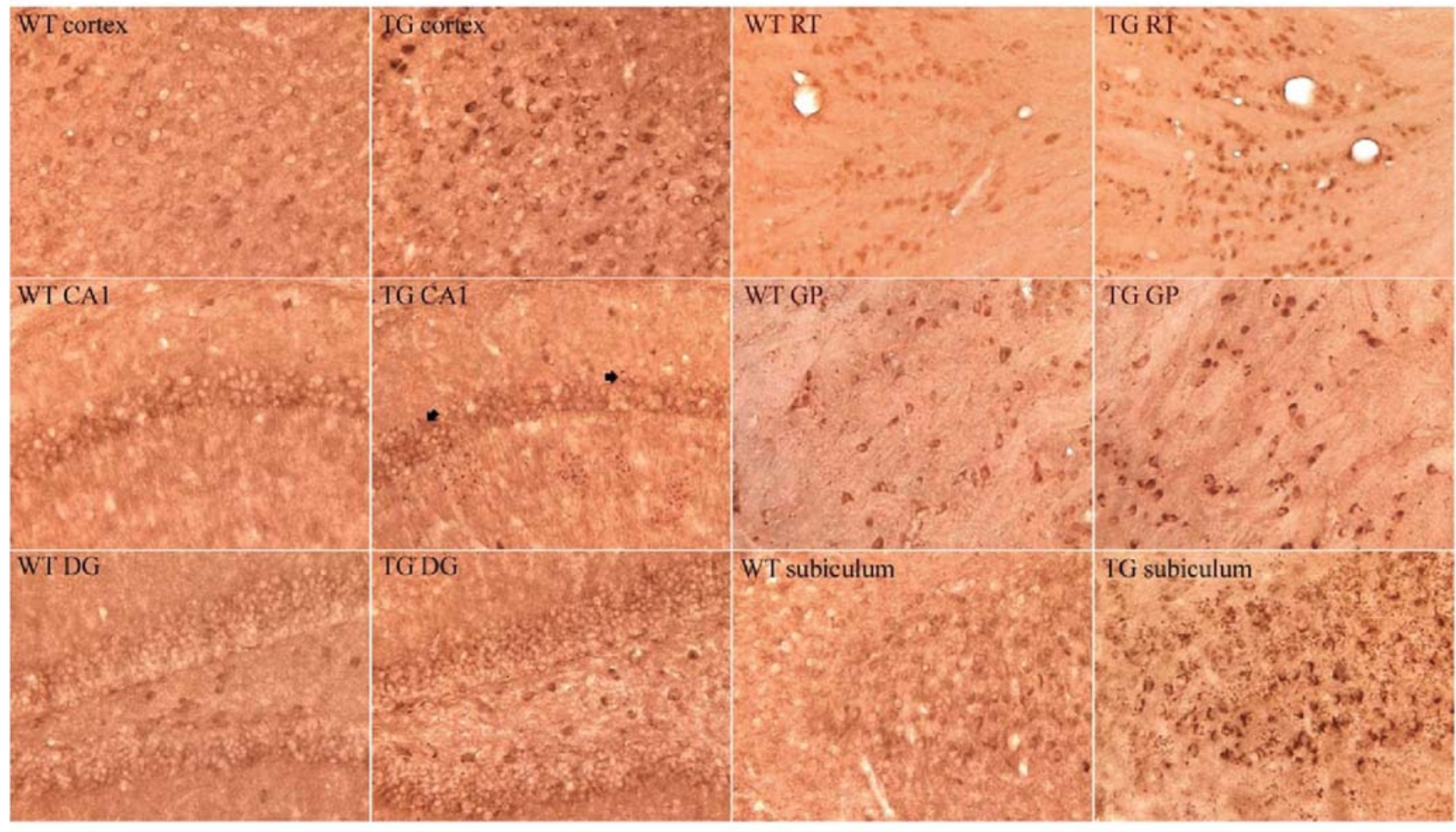

b
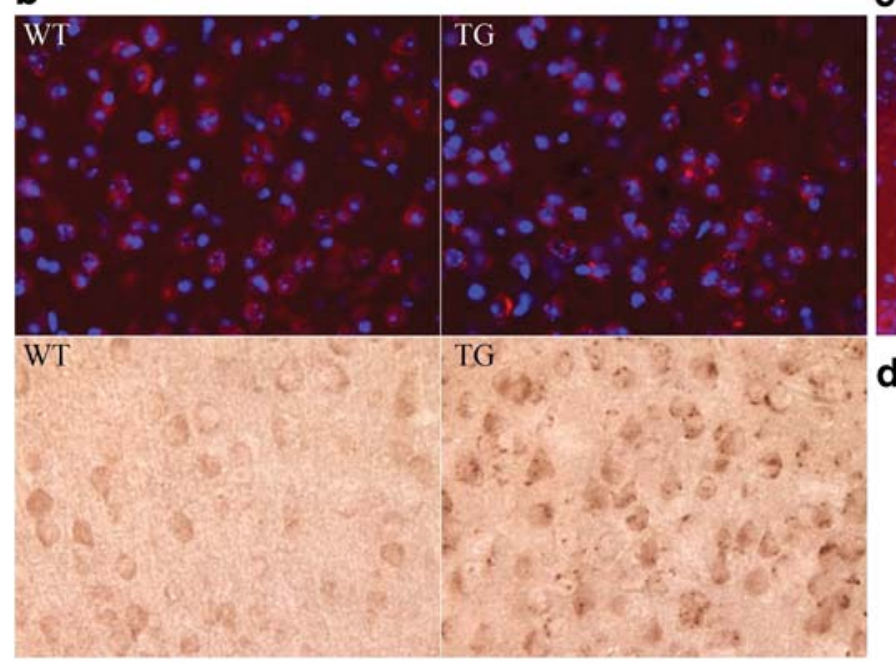

c

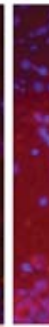

d

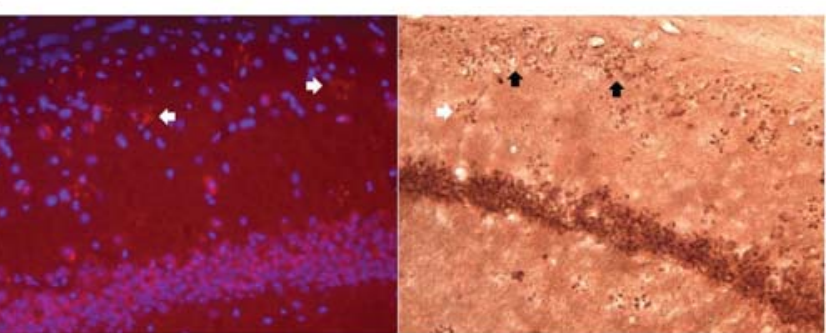

$\%$ mice with $A \beta$ deposits

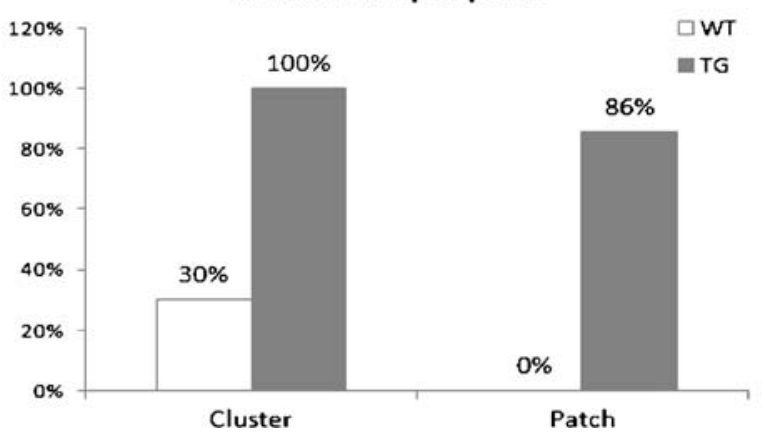

littermates displayed only background $A \beta$ staining. c Immunofluorescence and immunohistochemical staining reveals extracellular protofibrillar $\mathrm{A} \beta$ deposits in hippocampal CA1 region in TG mice. White arrows indicate $\mathrm{A} \beta$ clusters; black arrows indicate $\mathrm{A} \beta$ patches. d Extracellular $\mathrm{A} \beta$ deposits in 12-16-month-old TG mice $(n=7)$ and WT controls $(n=10)$
Fig. 2 Amyloidosis in COL25A1 TG mice. a Immunohistochemical staining with $A \beta$ antibody shows prominent $A \beta$ accumulation in the cortex, CA1, DG, subiculum, reticular thalamic nuclei $(R T)$, and globus pallidus $(G P)$ in 1-year-old TG mice but not in WT littermates. b Immunofluorescence and immunohistochemical staining with $A \beta$ antibody shows punctuate intracellular accumulations in TG mice. WT 


\section{COL25A1 triggers amyloidosis in TG mice}

To assess pathophysiological changes in the brains of COL25A1 TG mice, we performed immunohistochemical staining with an antibody specific for $A \beta$. $A \beta$ accumulation occurred concomitantly with the over-expression of COL25A1 protein and became apparent in TG mice at 1 year of age. Intracellular puncta were seen throughout the brain, particularly in the cortex, hippocampus, subiculum, and thalamus (Fig. 2a, b). Extracellular $A \beta$ deposits were found as individual clusters and in larger patches in the hippocampus (especially in the CA stratum oriens and stratum radiatum) and subiculum (Fig. $2 \mathrm{c}, \mathrm{d}$ ). $\mathrm{A} \beta$ clusters were observed in all seven TG mice analyzed at 12 16 months of age, but in only three $(30 \%)$ of ten WT littermates. $\mathrm{A} \beta$ patches were present in six TG mice $(86 \%)$ but in none of the WT littermates (Fig. 2d).Therefore, COL25A1 mice exhibited the amyloid accumulations characteristic of AD.

COL25A1 over-expression leads to behavioral alterations in TG mice

COL25A1 TG mice were analyzed in three behavioral assays. In the elevated plus maze test, TG mice spent more time and traveled farther in the open arms than the WT controls (Fig. 3a, b), suggesting disinhibition and reduced anxiety. ANOVA revealed that TG mice spent significantly more time in the open arms $(95.4 \pm 14.0$ vs. $39.9 \pm 7.7 \mathrm{~s}, F(1$, $33)=14.5, p=0.001 ; 31.8 \pm 4.7 \%$ vs. $13.3 \pm 2.6 \%, F(1,33)=$ 14.5, $p=0.001)$ and traveled farther $(423.0 \pm 69.6 \mathrm{~cm}$ vs. $170.2 \pm 27.3 \mathrm{~cm}, F(1,33)=15.6, p=0.0004 ; 26.9 \pm 4.1 \%$ vs. $11.2 \pm 2.1 \%, F(1,33)=14.1, p=0.001)$. Conversely, TG mice spent less time than WT mice in the closed arms $(153.9 \pm 12.4$ vs. $206.7 \pm 9.2$ s, $F(1,33)=11.9, p=0.002$; $51.3 \pm 4.1 \%$ vs. $68.9 \pm 3.1 \%, F(1,33)=11.9, p=0.002)$ and traveled shorter distances $(831.5 \pm 72.3$ vs. $1,091.2 \pm$ $59.7 \mathrm{~cm}, F(1,33)=7.4, p=0.010 ; 52.7 \pm 3.7 \%$ vs. $68.1 \pm$ $2.6 \%, F(1,33)=12.5, p=0.001)$. The numbers of basic and fine movements did not differ in the two groups (Fig. 3c).

In the open field test, TG mice spent more time exploring the center area, consistent with data findings in the elevated plus maze, as reflected in the ratio of central to peripheral activity $(0.204 \pm 0.039$ vs. $0.120 \pm 0.018, F$ $(1,33)=5.0, p=0.032$, Fig. $3 \mathrm{~d})$. Total locomotor activity was similar in the two groups (Fig. 3e).

In the Morris water maze, COL25A1 TG mice had significantly slower swim speeds in both the visible (Fig. 3f) and hidden (Fig. 3g) platform training. Repeatedmeasures ANOVA yielded a significant main effect for genotype in the visible $(F(1,33)=29.4, p<0.001)$ and hidden $(F(1,33)=23.1, p<0.001)$ sessions. The swimming speed of TG mice was also markedly slower in the probe
Fig. 3 Behavioral alterations of COL25A1 TG mice. a-c In the elevated plus maze, TG mice spent significantly more time (a) and traveled longer distances (b) in the open arms than WT littermates. They also spent less time (a) and traveled smaller distances (b) in the closed arms. No difference was found between these two groups in the intersection. Total basic and fine movements of TG mice were not different from WT littermates (c). d, e In the open field test, TG mice spent more time exploring the central zone than WT controls, resulting in a higher ratio of central to peripheral activity (d). Total locomotor activity was similar in the two groups (e). $\mathbf{f}-\mathbf{h}$ In the Morris water maze, the swimming speed of TG mice was significantly slower than that of WT controls in the visible (f) and hidden (g) platform training sessions and in the probe trials $(\mathbf{h})$. TG $(n=13)$ and WT littermates $(n=22)$ were used. Values are mean \pm SEM; $* * * p<0.001, * * p<0.01, * p<0.05$ (ANOVA)

trials $(14.7 \pm 0.9$ and $12.6 \pm 1.0 \mathrm{~cm} / \mathrm{s}$ vs. $18.5 \pm 0.4$ and $17.9 \pm$ $0.4 \mathrm{~cm} / \mathrm{s} ; F(1,33)=28.1, p<0.001$; Fig. $3 \mathrm{~h})$. As a result, latency to reach the platform was longer in TG mice during the visible sessions $(F(1,33)=4.2, p=0.049)$ and hidden sessions $(F(1,33)=6.8, p=0.013$; Fig. 1a in Electronic supplementary material). Spatial learning and memory of TG mice seemed unimpaired, as the distance crossed in the training sessions and the search patterns in the probe trials were similar in the two groups (Fig. 1b, c in Electronic supplementary material). Thus, apart from the slower swimming speed of TG mice, both groups performed similarly in the water maze test.

COL25A1 increases BACE1 and p35/25 expression in TG mice

To investigate the molecular mechanisms for the amyloid accumulation and behavioral alterations in COL25A1 TG mice, we analyzed brain regions for neuronal markers of AD pathology by Western blotting, immunohistochemical staining, or both. No differences between groups were observed in presenilin-1, nNOS, CD1b, calcineurin, 5HT, cfos, phosphor-CreB, $\beta$ catenin, N-cadherin, or connexin- 43 (data not shown).

However, TG mice had markedly higher levels of BACE1 (Fig. 4a) in cortex, hippocampus, thalamus, and subiculum. BACE1 is believed to be a key player in the pathogenesis of $\mathrm{AD}$, and changes in its expression or activity have been reported in $\mathrm{AD}$ patients and animal models that showed aberrant processing of APP and A $\beta$ accumulation $[2,3]$ The increase in BACE1 expression was consistent with the accumulation of $A \beta$ and was prominent in 1-year-old TG mice.

TG mice also had remarkably higher levels of p35/p25, the subunit that activates $\mathrm{Cdk} 5$, dysfunction of which has been implicated in AD [8]. Like BACE1, p35/p25 expression was increased in the cortex, hippocampus, thalamus, and subiculum in 1-year-old TG mice and paralleled the accumulation of $A \beta$ (Fig. $4 b$ ). 
a

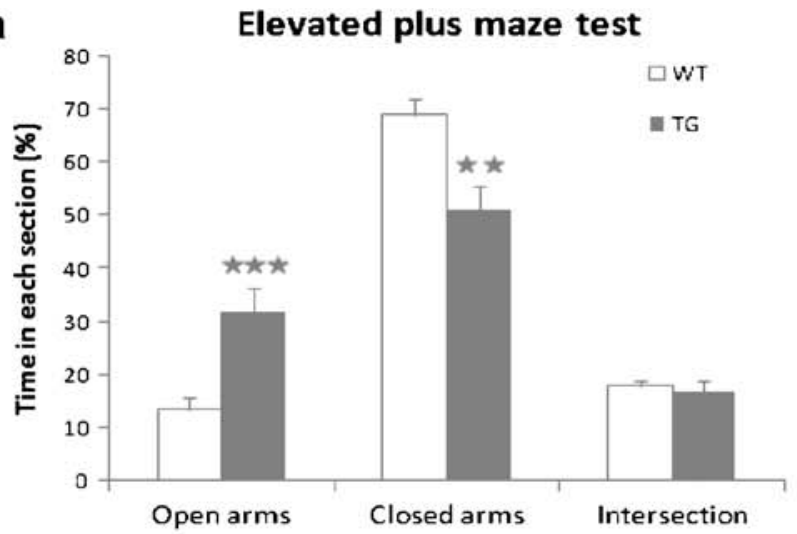

C

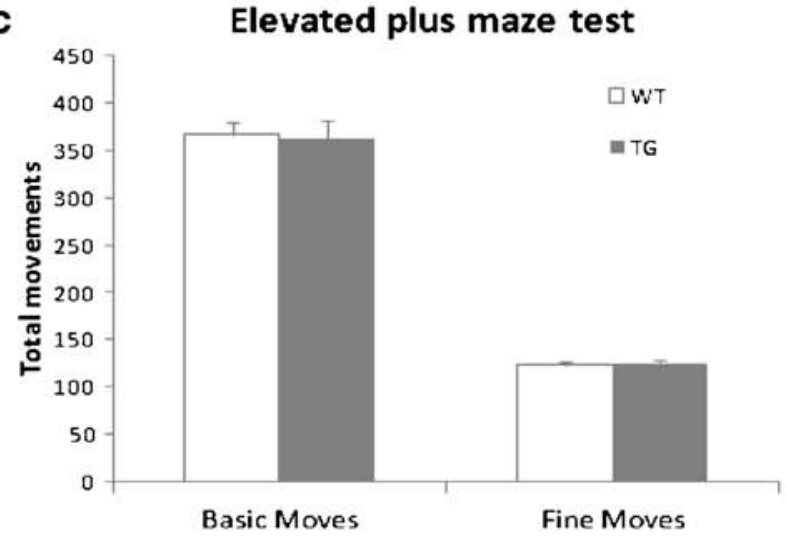

e

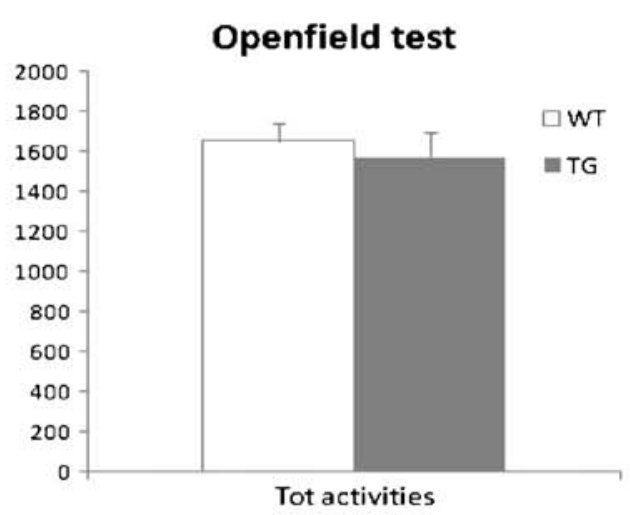

g

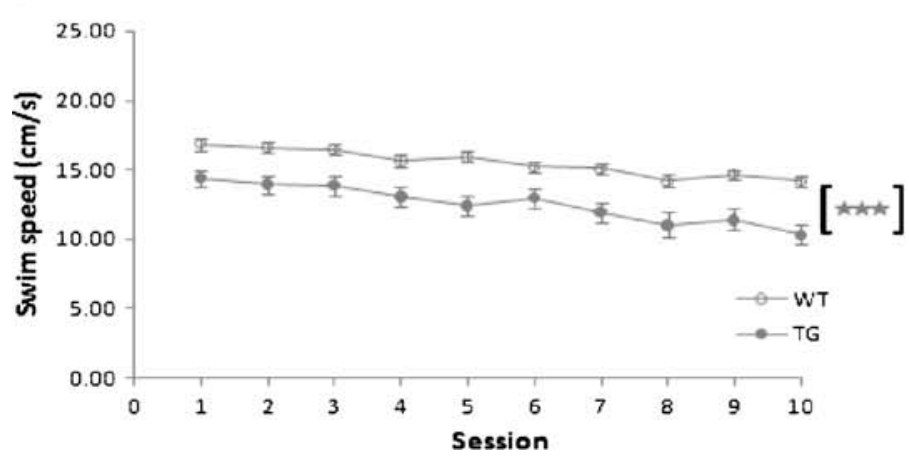

f b

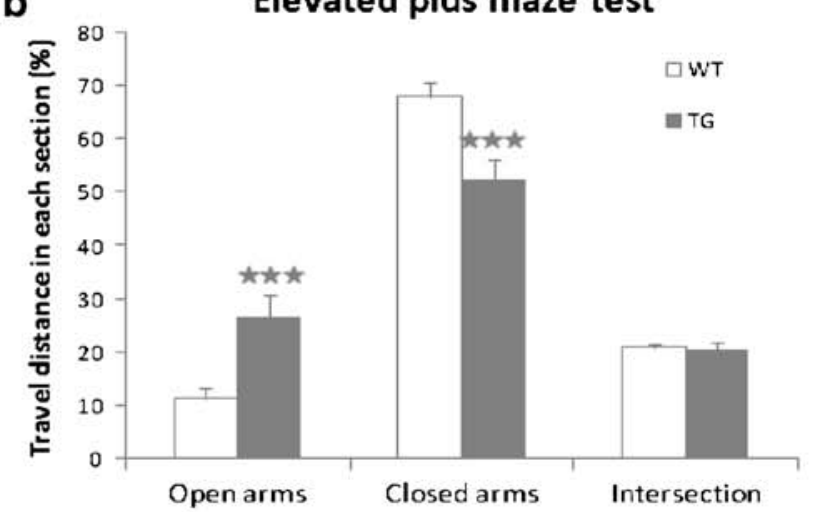

d

Openfield test
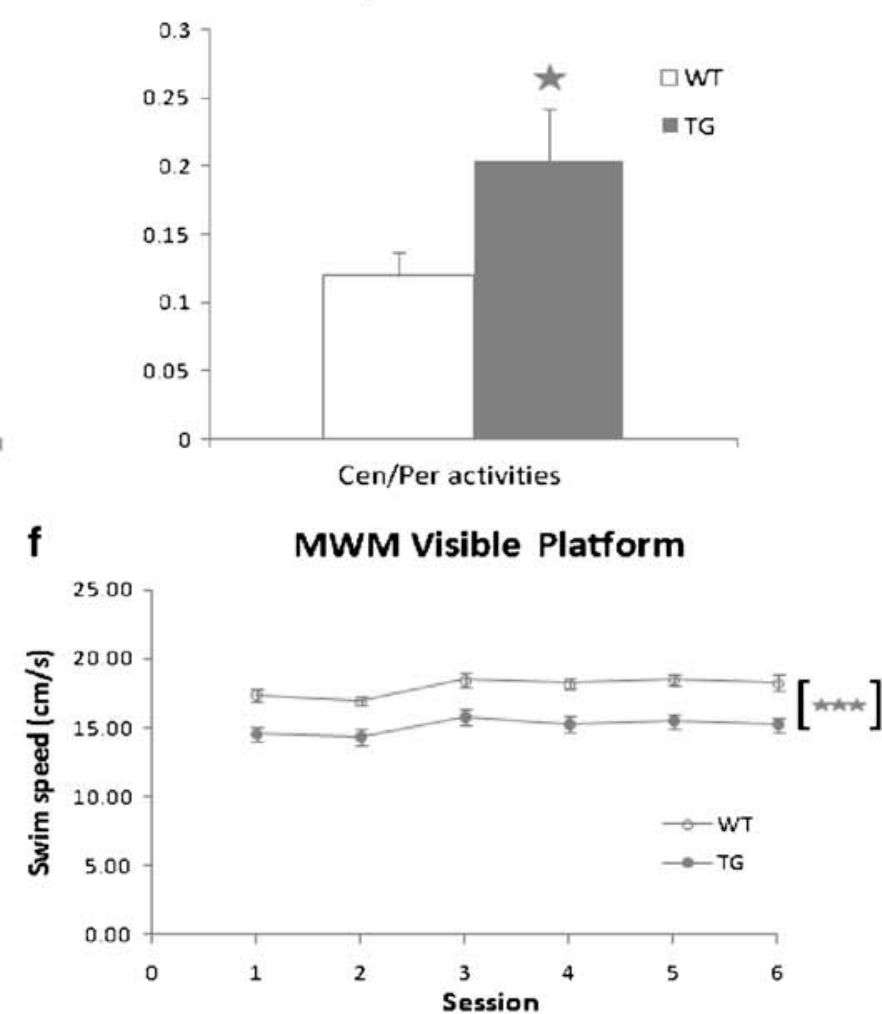

h

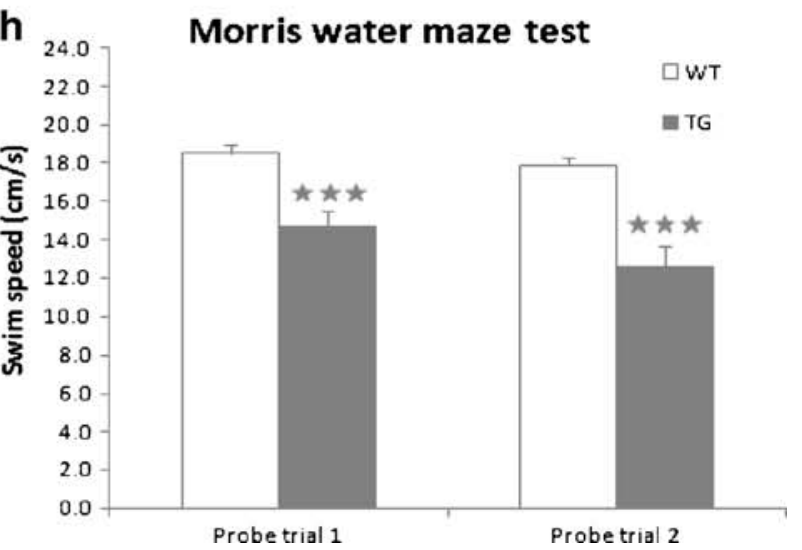


COL25A1 induces synaptophysin loss and astrocyte activation in TG mice

The neural dysfunction in AD likely reflects synaptic damage and disruption of plasticity at synapses. Loss of synaptic proteins is more severe in $\mathrm{AD}$ patients and mouse models $[20,21]$. To determine whether COL25A1 overexpression induces such abnormalities, we measured the levels of synaptophysin, a synapse-specific protein, in the forebrains of 20 -month-old mice by Western blotting (Fig. 4c). Synaptophysin levels were $28 \%$ lower in TG mice than WT controls $(p=0.05$; Fig. $4 d)$, indicating synapse damage in COL25A1 mice. Since reactive astrocytes are often observed in AD brains and mouse models [22], we looked for astrogliosis in COL25A1 TG mice. Immunohistochemical analysis revealed increased levels of staining for GFAP, a marker of astrocyte activation, in the brains of 16-month-old COL25A1 TG mice, particularly in the subiculum (Fig. 4e).

$\mathrm{NC} 1, \mathrm{NC} 2$, and NC3 motifs are important for the induction of BACE1 by COL25A1 in stable cell lines

To further explore the molecular mechanism of COL25A1 in mediating AD-like pathology, we constructed expression plasmids encoding human full-length COL25A1 (WT) or COL25A1 with deletions of the COL1 $(\triangle \mathrm{COL} 1), \mathrm{NC} 1$ $(\triangle \mathrm{NC} 1), \mathrm{NC} 2(\triangle \mathrm{NC} 2)$, or $\mathrm{NC} 3(\triangle \mathrm{NC} 3)$ domains. Each construct was transfected into cultured SH-SY5Y cells, and lines with stable expression were selected. Normal cell membrane localization was observed in cells overexpressing WT COL25A1 (Fig. 5a), $\triangle \mathrm{NC} 2$, and $\triangle \mathrm{NC} 3$. However, in cells expressing $\triangle \mathrm{NC} 1, \mathrm{COL} 25 \mathrm{~A} 1$ was retained in the cytoplasm, indicating a critical role for the $\mathrm{NC} 1$ motif in normal cellular localization of COL25A1.

Next, we examined BACE1 levels in these cell lines by Western blotting (Fig. 5b) and densitometry (Fig. 5c). WT COL25A1 increased BACE1 levels 2.00 \pm 0.12 -fold $(p=0.001)$. BACE1 levels were not affected by $\triangle \mathrm{COL} 1$ and were only slightly reduced from WT levels by $\triangle \mathrm{NC} 1$ (1.45 \pm 0.16 -fold, $p=0.05)$, which was mislocalized. However, the effect of WT COL25A1 was markedly reduced by $\triangle \mathrm{NC} 2(0.92 \pm 0.02$-fold, $p=0.0008)$ and $\triangle \mathrm{NC} 3(0.88 \pm$ $0.13, p=0.003)$. Together, these results suggested that $\mathrm{NC}$ domains (especially $\mathrm{NC} 2$ and $\mathrm{NC} 3$ ) are intimately involved in the induction of BACE1 by COL25A1 protein.

\section{Discussion}

This study shows that over-expression of COL25A1 in TG mice results in prominent accumulation of $A \beta$ and increased levels of $\mathrm{p} 35 / \mathrm{p} 25$ and BACE1. These changes
Fig. 4 Molecular changes in COL25A1 TG mouse brains. a, b Immunohistochemical staining shows greater BACE1 (a) and p35/p25 (b) immunoreactivity in cortex, CA1, DG, reticular thalamic nuclei $(R T)$, globus pallidus $(G P)$, and subiculum of TG mice than WT littermates. c, d Western blot analysis of forebrain extracts shows synaptophysin loss in TG mice. Values are mean \pm SEM; ${ }^{*} p<0.05(t$ test). e Immunohistochemical staining of brain sections with antiGFAP antibody shows astrocyte activation in the subiculum of TG mice

were accompanied by synaptophysin loss, astrocyte activation, and alterations on elevated plus maze and open field test. The NC1, NC2, and NC3 domains of COL25A1 were important for induction of BACE1 in stably transfected SHSY5Y cell lines. Our findings suggest that COL25A1 plays a critical role in $\mathrm{AD}$ pathogenesis, perhaps by acting as an amyloidogenic cofactor in vivo.

Prominent $\mathrm{A} \beta$ accumulation was detected in two independent COL25A1 transgenic lines (861 and 797) by immunohistochemical staining with $A \beta 1-40 / 42$ antibody. Although it is possible that the detected peptides were $A \beta$ containing APP derivatives, these peptides cannot be fulllength APP, as the well-characterized full-length APP antibody $22 \mathrm{C} 11$ did not detect obvious change in these mice (data not shown).

The intracellular $A \beta$ aggregation could result from increased production of $A \beta$, abnormal retention of $A \beta$ within the secretory system, or enhanced uptake of secreted $A \beta$ by the endocytic pathway [23]. No obvious change in APP levels was found in these mice by immunohistochemistry. However, BACE1 levels were increased in both TG lines, suggesting that increased APP processing was responsible for the $A \beta$ accumulation. BACE1 levels were also elevated in stably transfected SH-SY5Y cells overexpressing COL25A1. Since extracellular A $\beta$ deposits were observed in the mice, it is unlikely that an aberrant secretory pathway was the major cause of $A \beta$ accumulation. Another possibility is that the membrane-tethered (precursor) form of COL25A1 favors the internalization of secreted $A \beta$ by binding to extracellular $A \beta$ aggregates, resulting in abnormal accumulation of intracellular $\mathrm{A} \beta$.

The extracellular A $\beta$ deposits in COL25A1 TG mice were clusters or patches evolving into protofibrillar structures. In contrast to many other AD models, these mice did not have compact or diffuse plaques at 16 months of age. Monomeric $A \beta$ is thought to form oligomeric or protofribrillar intermediates that mature into the amyloid fibrils found in plaques. Evidently, the protofibrillar deposits in COL25A1 TG mice did not progress to form fibrils in mice up to 16 months of age. Since secreted COL25A1 builds up extracellular fibrillar deposits in TG mice, it is possible that COL25A1 binds to $A \beta$ deposits and slows $A \beta$ fibril elongation, as suggested by in vitro binding assays [14]. The weaker amyloidogenic ability of mouse $A \beta$ peptides 
a

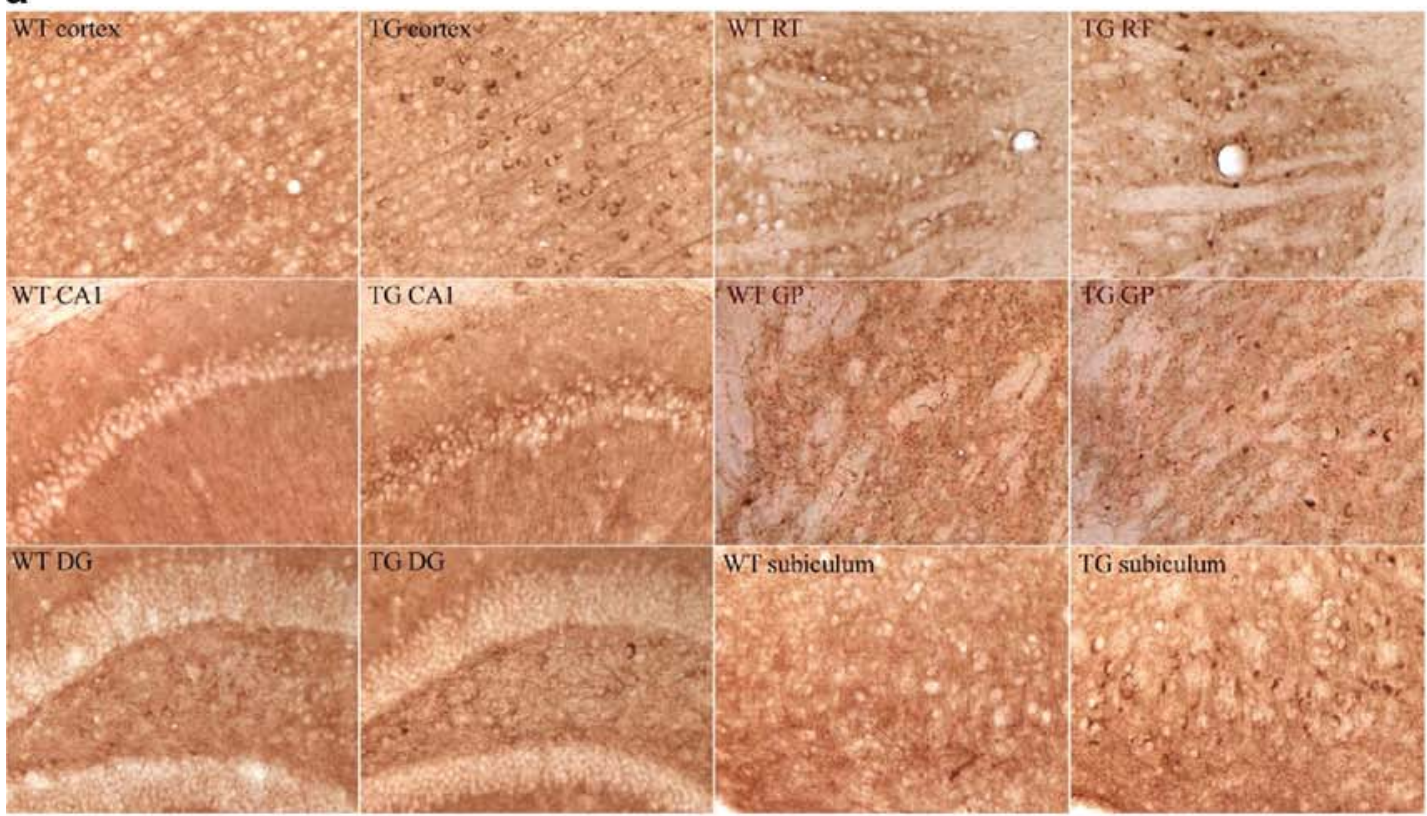

b
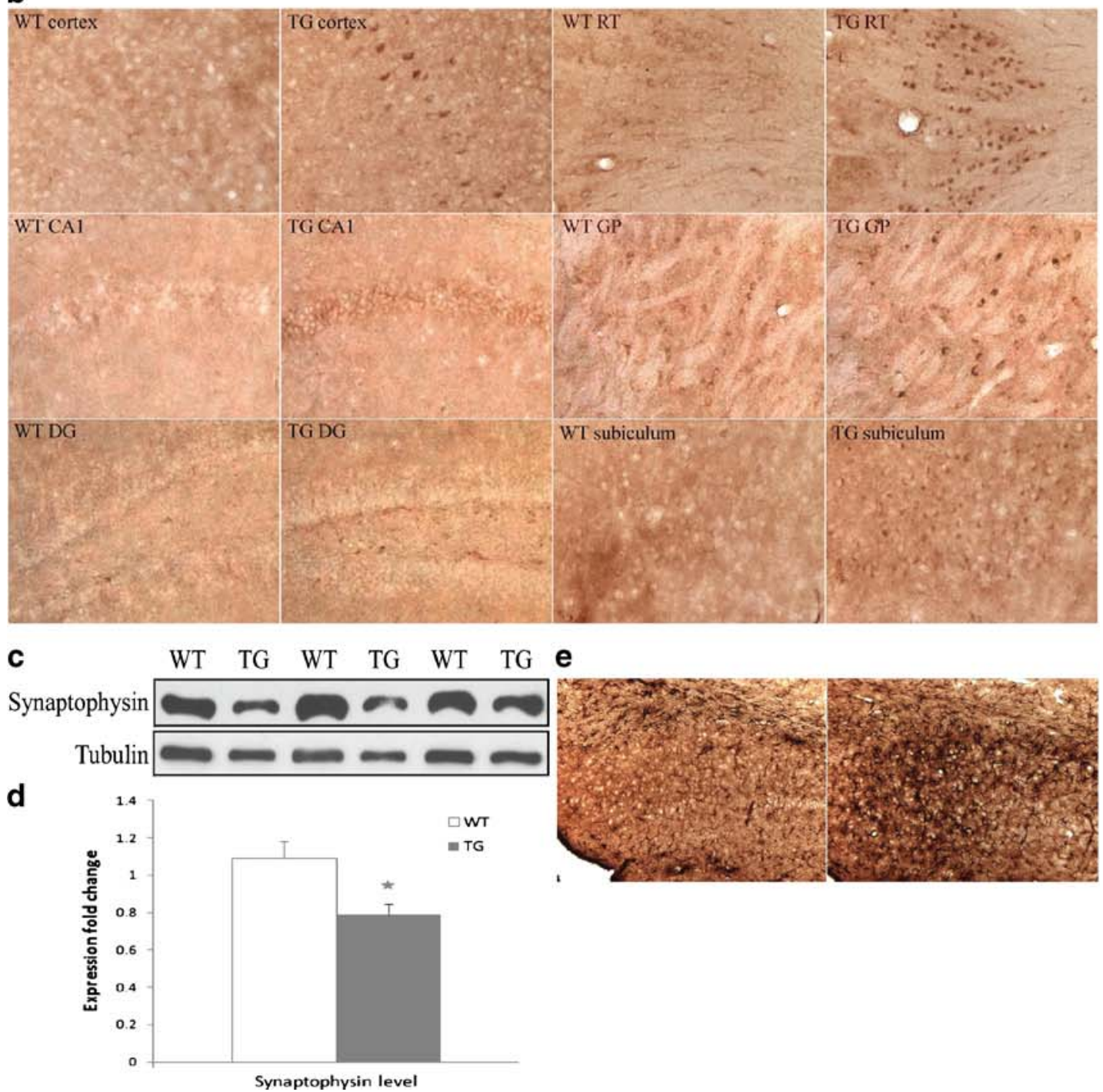

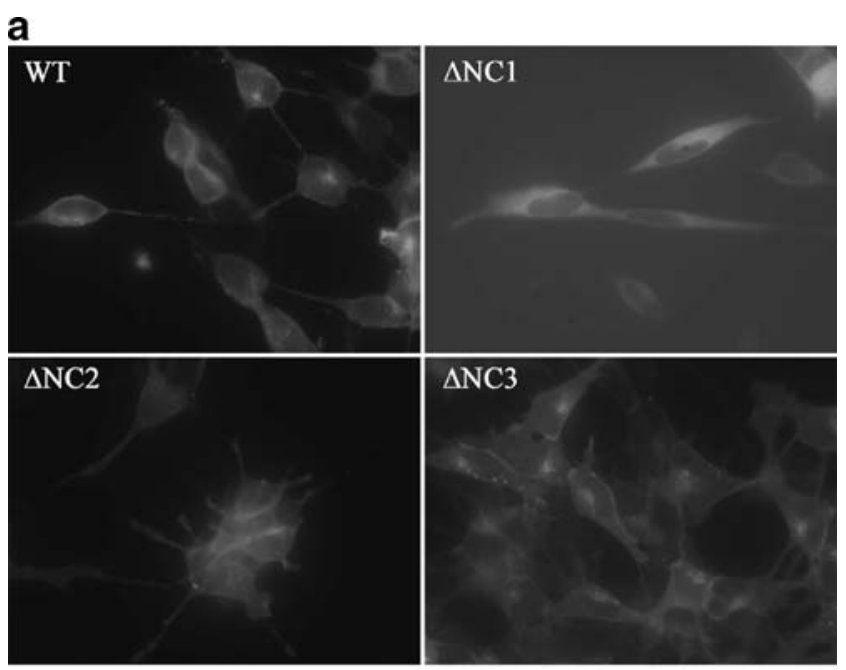

b

SH WT $\triangle$ Coll $\triangle \mathrm{NCl} \quad \triangle \mathrm{NC2} \quad \triangle \mathrm{NC} 3$
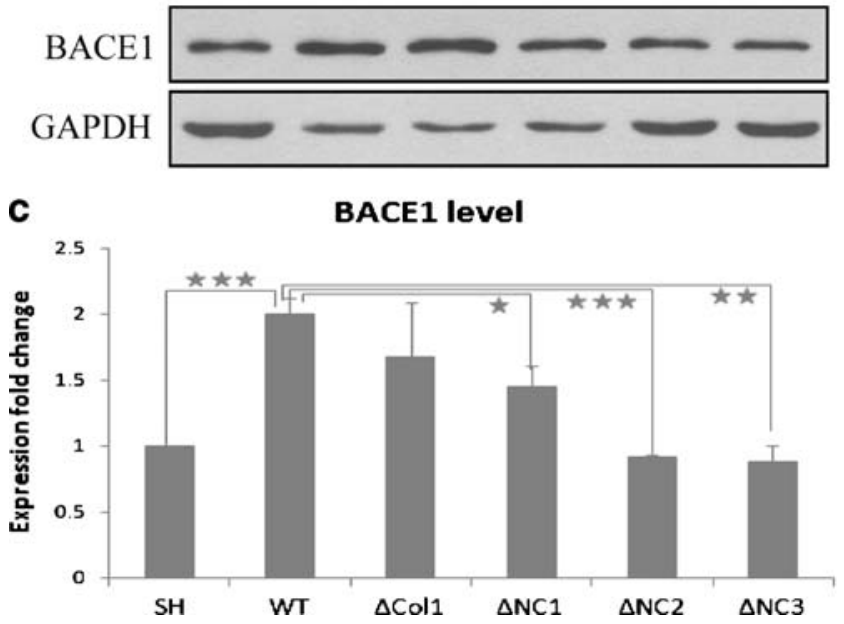

Fig. 5 NC1, NC2, and NC3 motifs in COL25A1 are important for the induction of BACE1 by COL25A1. SH-SY5Y cells were stably transfected with WT, $\triangle \mathrm{NC} 1, \triangle \mathrm{NC} 2$, or $\triangle \mathrm{NC} 3 \mathrm{COL} 25 \mathrm{~A} 1$ fused to EGFP. a WT, $\triangle \mathrm{NC} 2$, and $\triangle \mathrm{NC} 3$ proteins showed normal membrane localization, but $\triangle \mathrm{NC} 1$ showed aberrant cytoplasmic distribution. b BACE1 levels in untransfected $(\mathrm{SH})$ and transfected cells. Shown here is a representative Western blot from three independent experiments. GAPDH was used as a loading control. $\mathbf{c}$ Densitometric quantification of BACE1 levels relative to level in untransfected cells. Values are mean \pm SEM; $* * * p<0.001, * * p<0.01, * p<0.05$ ( $t$ test $)$

might also have contributed to the lack of plaque formation $[24,25]$. It is unlikely that the age of the mice at testing (16 months) contributed markedly to the lack of plaque formation, since intracellular $A \beta$ accumulation was apparent as early as 6 months of age, when distinct extracellular A $\beta$ protofibrillar deposits were seen in one of three TG mice but in none of three WT littermates. Nonetheless, further experiments are needed to test whether they will develop fibrillar plaques at more advanced ages.

In recent years, the amyloid cascade hypothesis has been modified to reflect experimental evidence that oligomers of $\mathrm{A} \beta$, not monomers or amyloid fibrils, are the major initiators of $\mathrm{AD}$ pathology. A growing body of report indicates that oligomeric/protofibrillar $A \beta$ species are toxic while mature $A \beta$ fibers are largely inert [26-28]. Our findings in COL25A1 mice support the modified amyloid hypothesis, which emphasizes the critical role of oligomeric/protofibrillar $\mathrm{A} \beta$ accumulation in $\mathrm{AD}$ pathology $[23,29]$.

Although fibrillar plaques did not form in COL25A1 TG mice, $A \beta$ accumulation induced many of the pathogenic events proposed by the amyloid cascade hypothesis [1], including synaptic injury, an inflammatory response, altered kinase/phosphatase activities, and neuronal dysfunction. Both synaptophysin loss and astrocyte lesions were detected in COL25A1 TG mice along with the $\mathrm{A} \beta$ accumulation, indicating abnormalities of neurites. Interestingly, COL25A1 mice had elevated levels of the activator subunit (p35/p25) of Cdk5 kinase, which has been implicated in regulating synaptic plasticity, emotionality, learning, and memory in vivo [30,31]. COL25A1 mice also exhibited reduced emotionality or disinhibition in behavioral tests, suggesting neuronal dysfunction. COL25A1 mice spent more time exploring the open arms in the elevated plus maze and in the center area in the open field test, indicating reduced anxiety. Similar behaviors have also been noted in other AD mouse models [32].

Another noticeable behavioral change of COL25A1 mice was their significantly reduced swimming speed in the Morris water maze test. To our knowledge, this characteristic has only been reported in $\alpha$ CamKII ${ }^{\mathrm{T} 286 \mathrm{~A}}$ mutant mice, which might reflect their 129S2/SvHsd hybrid background [33]. The reduced swimming speed of COL25A1 mice did not result from floating behavior, since the average speed was above $10 \mathrm{~cm} / \mathrm{s}$ in each session. Nor was disturbance of

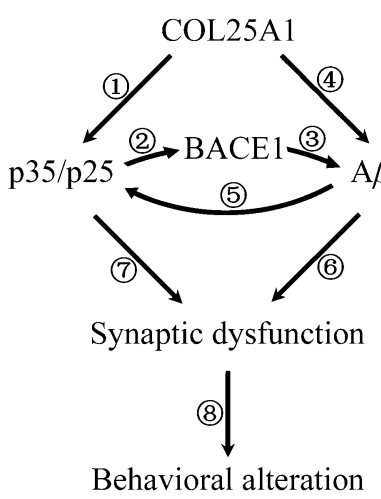

Fig. 6 Hypothetical model of the AD-like pathogenic process in COL25A1 mice. Over-expression of COL25A1 (1) leads to increased p35/p25 levels (2), which promote BACE1 expression and (3) accelerate $A \beta$ generation and accumulation. 4 Direct binding of COL25A1 to $\mathrm{A} \beta$ exacerbates $\mathrm{A} \beta$ accumulation and deposition. 5 Accumulated $A \beta$ causes dysregulation of $p 35 / p 25$. Together, $A \beta$ accumulation (6) and dysregulated p35/p25 (7) induce synaptic dysfunction, which leads to the behavioral changes (8) in COL25AI TG mice 
motor function responsible, as locomotor activity in the elevated plus maze and open field tests was unimpaired, and COL25A1 mice perform normally in rotarod and tightrope tests (unpublished data). The slow swimming speed was evident from the beginning of the test and was sharply reduced when the platform was removed during the probe trials. These unique behavioral characteristics might reflect motivational difficulties.

COL25A1 mice exhibited no deficits in spatial learning or working memory performance in the water maze test. This was surprising, considering the prominent, widespread accumulation of $A \beta$ and increased levels of BACE1 and $\mathrm{p} 35 / \mathrm{p} 25$. The absence of learning and retention deficits in the water maze has been noted in some AD mouse models $[34,35]$, although others did have cognitive deficits [36, 37]. Although the reasons are unclear [38], such discrepancies are likely to be due, in part, to differences in murine and human physiology and in the toxicity of intracellular $\mathrm{A} \beta$. Genetic differences in specific species or strains may substantially modify detectable phenotypes in mouse models [39]. It is also possible that over-expression of COL25A1 might activate other pathways to balance the toxicity of $A \beta$, thus eliminate the spatial memory deficits found in some $\mathrm{AD}$ models.

Motifs in the $\mathrm{NC} 1, \mathrm{NC} 2$, and $\mathrm{NC} 3$ domains of COL25A1 were important for induction of BACE1 in stably transfected SH-SY5Y cell lines. Deletion of the NC1 motif caused the protein to lose its ability to traffic to cell membranes, implying its importance for cellular localization. Deletion of the NC2 or NC3 motif did not impair the trafficking of COL25A1 but attenuated its effect on BACE1. The NC2 domain harbors one positively charged amino acid-rich $A \beta$ binding motif that is a predicted binding domain for heparin [40]. The NC3 domain contains one coiled-coil motif thought to be necessary for the triplehelix structure of COL25A1 collagenous fibrils [15]. The COL1 domain mediates the interaction with $\mathrm{A} \beta$, which requires COL25A1 to form a triple helix structure [15]. In stably transfected SH-SY5Y cell lines, deletion of the COL1 motif did not affect the localization of COL25A1 or its effect on BACE1 expression. These results suggest that the integrity and charge state of the protein structure and the interactions among related proteins contribute to the pathologic changes caused by COL25A1 over-expression.

Our findings suggest a model in which COL25A1 fulfills a dual function in the amyloid pathogenesis of AD (Fig. 6). On the one hand, over-expression of COL25A1 increases p35/p25 levels, leading to increased BACE1 levels [9, 10], which promote APP processing, accelerate A $\beta$ generation, and culminate in intracellular and extracellular accumulation of $A \beta$. On the other hand, COL25A1 might directly bind to $A \beta$ aggregates, slow $A \beta$ fibril elongation, and lead to $A \beta$ aggregation in the toxic protofibrillar intermediary form. The resulting increase in $A \beta$ toxicity might cause dysregulation of $\mathrm{p} 35 / \mathrm{p} 25[5,6]$, further increasing $A \beta$ production through BACE1. $\mathrm{A} \beta$ and $\mathrm{p} 35 / \mathrm{p} 25$ toxicity disrupts synaptic activity and induces local inflammatory response. Ultimately, these changes translate into the behavioral alterations observed in COL25A1 mice.

Further investigations are needed to test our hypothesis and determine how COL25A1 induces dysregulation of p35/p25. Our COL25A1 TG mouse lines will be useful for exploring the mechanisms involved in the initiation and progression of $\mathrm{AD}$. In addition, modulation of COL25A1 function may represent a novel therapeutic approach to prevent or delay the amyloid pathology of AD.

Acknowledgments We thank Drs. Pico Caroni and Corinna Schneider for Thy-1.2 expression cassette, Dr. Takeshi Iwatsubo for NC4 antibody, and Drs. Li Gan and Lennart Mucke for valuable suggestions. This work was supported in part by Sandler Neurogenetics Fund to UCSF.

Ethical standards These experiments comply with the current laws of USA.

Disclosure statement The authors declare that they have no conflict of interest to disclose.

Open Access This article is distributed under the terms of the Creative Commons Attribution Noncommercial License which permits any noncommercial use, distribution, and reproduction in any medium, provided the original author(s) and source are credited.

\section{References}

1. Hardy J, Selkoe DJ (2002) The amyloid hypothesis of Alzheimer's disease: progress and problems on the road to therapeutics. Science 297:353-356

2. Yang LB, Lindholm K, Yan R et al (2003) Elevated beta-secretase expression and enzymatic activity detected in sporadic Alzheimer disease. Nat Med 9:3-4

3. Bodendorf U, Danner S, Fischer F et al (2002) Expression of human beta-secretase in the mouse brain increases the steady-state level of beta-amyloid. J Neurochem 80:799-806

4. Chiocco MJ, Kulnane LS, Younkin L et al (2004) Altered amyloid-beta metabolism and deposition in genomic-based betasecretase transgenic mice. J Biol Chem 279:52535-52542

5. Lopes JP, Oliveira CR, Agostinho P (2007) Role of cyclindependent kinase 5 in the neurodegenerative process triggered by amyloid-Beta and prion peptides: implications for Alzheimer's disease and prion-related encephalopathies. Cell Mol Neurobiol 27:943-957

6. Seyb KI, Ansar S, Li G et al (2007) p35/Cyclin-dependent kinase 5 is required for protection against beta-amyloid-induced cell death but not tau phosphorylation by ceramide. J Mol Neurosci 31:23-35

7. Patrick GN, Zukerberg L, Nikolic M et al (1999) Conversion of p35 to p25 deregulates Cdk5 activity and promotes neurodegeneration. Nature 402:615-622 
8. Tseng HC, Zhou Y, Shen Y et al (2002) A survey of Cdk5 activator p35 and p25 levels in Alzheimer's disease brains. FEBS Lett 523:58-62

9. Cruz JC, Kim D, Moy LY et al (2006) p25/cyclin-dependent kinase 5 induces production and intraneuronal accumulation of amyloid beta in vivo. J Neurosci 26:10536-10541

10. Wen Y, Yu WH, Maloney B et al (2008) Transcriptional regulation of beta-secretase by p25/cdk5 leads to enhanced amyloidogenic processing. Neuron 57:680-690

11. Hashimoto T, Wakabayashi T, Watanabe A et al (2002) CLAC: a novel Alzheimer amyloid plaque component derived from a transmembrane precursor, CLAC-P/collagen type XXV. EMBO J 21:1524-1534

12. Kowa H, Sakakura T, Matsuura Y et al (2004) Mostly separate distributions of CLAC- versus Abeta40- or thioflavin Sreactivities in senile plaques reveal two distinct subpopulations of beta-amyloid deposits. Am J Pathol 165:273-281

13. Forsell C, Bjork BF, Lilius L et al (2008) Genetic association to the amyloid plaque associated protein gene COL25A1 in Alzheimer's disease. Neurobiol Aging . doi:10.1016/j.neurobio laging.2008.04.009

14. Kakuyama H, Soderberg L, Horigome K et al (2005) CLAC binds to aggregated Abeta and Abeta fragments, and attenuates fibril elongation. Biochemistry 44:15602-15609

15. Osada Y, Hashimoto T, Nishimura A et al (2005) CLAC binds to amyloid beta peptides through the positively charged amino acid cluster within the collagenous domain 1 and inhibits formation of amyloid fibrils. J Biol Chem 280:8596-8605

16. Söderberg L, Dahlqvist C, Kakuyama H et al (2005) Collagenous Alzheimer amyloid plaque component assembles amyloid fibrils into protease resistant aggregates. FEBS J 272:2231-2236

17. Roberson ED, Scearce-Levie K, Palop JJ et al (2007) Reducing endogenous tau ameliorates amyloid beta-induced deficits in an Alzheimer's disease mouse model. Science 316:750-754

18. Ghoshal N, Garcia-Sierra F, Fu Y et al (2001) Tau-66: evidence for a novel tau conformation in Alzheimer's disease. J Neurochem 77:1372-1385

19. Knuesel I, Nyffeler M, Mormede C et al (2007) Age-related accumulation of Reelin in amyloid-like deposits. Neurobiol Aging . doi:10.1016/j.neurobiolaging.2007.08.011

20. Sze CI, Troncoso JC, Kawas C et al (1997) Loss of the presynaptic vesicle protein synaptophysin in hippocampus correlates with cognitive decline in Alzheimer disease. J Neuropathol Exp Neurol 56:933-944

21. Mucke L, Masliah E, Yu GQ et al (2000) High-level neuronal expression of abeta 1-42 in wild-type human amyloid protein precursor transgenic mice: synaptotoxicity without plaque formation. J Neurosci 20:4050-4058

22. Ingelsson M, Fukumoto H, Newell KL et al (2004) Early Abeta accumulation and progressive synaptic loss, gliosis, and tangle formation in AD brain. Neurology 62:925-931

23. LaFerla FM, Green KN, Oddo S (2007) Intracellular amyloid-beta in Alzheimer's disease. Nat Rev Neurosci 8:499-509

24. De Strooper B, Simons M, Multhaup G et al (1995) Production of intracellular amyloid-containing fragments in hippocampal neurons expressing human amyloid precursor protein and protection against amyloidogenesis by subtle amino acid substitutions in the rodent sequence. EMBO J 14:4932-4938

25. Huang J, Yao Y, Lin J et al (2004) The solution structure of rat Abeta-(1-28) and its interaction with zinc ion: insights into the scarcity of amyloid deposition in aged rat brain. J Biol Inorg Chem 9:627-635

26. Kayed R, Head E, Thompson JL et al (2003) Common structure of soluble amyloid oligomers implies common mechanism of pathogenesis. Science 300:486-489

27. Cheng IH, Scearce-Levie K, Legleiter J et al (2007) Accelerating amyloid-beta fibrillization reduces oligomer levels and functional deficits in Alzheimer disease mouse models. J Biol Chem 282:23818-23828

28. Martins IC, Kuperstein I, Wilkinson H et al (2008) Lipids revert inert Abeta amyloid fibrils to neurotoxic protofibrils that affect learning in mice. EMBO J 27:224-233

29. Billings LM, Oddo S, Green KN et al (2005) Intraneuronal Abeta causes the onset of early Alzheimer's disease-related cognitive deficits in transgenic mice. Neuron 45:675-688

30. Sananbenesi F, Fischer A, Wang X et al (2007) A hippocampal Cdk5 pathway regulates extinction of contextual fear. Nat Neurosci 10:1012-1019

31. Cheung ZH, Fu AK, Ip NY (2006) Synaptic roles of Cdk5: implications in higher cognitive functions and neurodegenerative diseases. Neuron 50:13-18

32. Lalonde R, Lewis TL, Strazielle C et al (2003) Transgenic mice expressing the betaAPP695SWE mutation: effects on exploratory activity, anxiety, and motor coordination. Brain Res 977:38-45

33. Need AC, Giese KP (2003) Handling and environmental enrichment do not rescue learning and memory impairments in alphaCamKII(T286A) mutant mice. Genes Brain Behav 2:132139

34. Holcomb LA, Gordon MN, Jantzen P et al (1999) Behavioral changes in transgenic mice expressing both amyloid precursor protein and presenilin-1 mutations: lack of association with amyloid deposits. Behav Genet 29:177-185

35. King DL, Arendash GW (2002) Behavioral characterization of the Tg2576 transgenic model of Alzheimer's disease through 19 months. Physiol Behav 75:627-642

36. Chen G, Chen KS, Knox J et al (2000) A learning deficit related to age and beta-amyloid plaques in a mouse model of Alzheimer's disease. Nature 408:975-979

37. Kelly PH, Bondolfi L, Hunziker D et al (2003) Progressive agerelated impairment of cognitive behavior in APP23 transgenic mice. Neurobiol Aging 24:365-378

38. Duyckaerts C, Potier MC, Delatour B (2008) Alzheimer disease models and human neuropathology: similarities and differences. Acta Neuropathol 115:5-38

39. Magara F, Muller U, Li ZW et al (1999) Genetic background changes the pattern of forebrain commissure defects in transgenic mice underexpressing the beta-amyloid-precursor protein. Proc Natl Acad Sci U S A 96:4656-4661

40. Söderberg L, Kakuyama H, Möller A et al (2005) Characterization of the Alzheimer's disease-associated CLAC protein and identification of an amyloid beta-peptide-binding site. J Biol Chem 280:1007-1015 